\title{
Regulation of Gene Expression during Aerobic Germination of Mucor racemosus Sporangiospores
}

\author{
By JOHN E. LINZ† AND MICHAEL ORLOWSKI* \\ Department of Microbiology, Louisiana State University, Baton Rouge, LA 70803, USA
}

(Received 22 May 1986)

\begin{abstract}
The pool of mRNA stored in dormant sporangiospores of Mucor racemosus and expressed during early germination in air has been investigated. Total RNA was extracted from dormant and germinating spores and translated in a cell-free rabbit reticulocyte system containing L$\left[{ }^{35} \mathrm{~S}\right]$ methionine. Isotopically labelled in vitro translation products were analysed by PAGE and autoradiography and were compared with labelled proteins synthesized in vivo at the same stages of development. This comparison revealed several significant findings about the fates of individual mRNA populations as templates in translation: (i) a pool of mRNA, presumably represented entirely or in part by a recoverable polyadenylated RNA fraction, can be extracted from dormant spores in a translatable form; (ii) most of the differential gene expression displayed at the level of protein synthesis during germination results from concomitant changes in functional mRNA levels; (iii) some of the stored mRNA species may be activated and others inactivated by post-transcriptional processing mechanisms; and (iv) a small population of gene products may be regulated at the level of selective translation of pre-existing messages.
\end{abstract}

\section{INTRODUCTION}

When grown on solid medium in air, the dimorphic zygomycete Mucor racemosus produces abundant aerial hyphae, each terminating in a spore-laden sac. Upon germination, these asexual sporangiospores develop directly into that vegetative morphology appropriate to the environmental conditions (Bartnicki-Garcia, 1973; Sypherd et al., 1979). Past work has focussed upon molecular events during the aerobic germination of Mucor sporangiospores ultimately leading to the production of hyphal germ tubes (Linz \& Orlowski, 1982, 1984; Orlowski, 1979; Orlowski \& Sypherd, 1978; Tripp \& Paznokas, 1981, 1982a, $b$; Wertman \& Paznokas, 1981). We determined that $M$. racemosus sporangiospores contained a pool of stored mRNA (Linz \& Orlowski, 1982). Translation of this mRNA pool commenced as soon as the spores were introduced into nutrient medium and approximately $20 \mathrm{~min}$ before RNA synthesis began (Linz \& Orlowski, 1982). During the first hour of germination the rate of protein synthesis increased several fold. This increased rate of protein synthesis was not simply due to an increase in the synthesis of all proteins. Germinating spores displayed both qualitative and quantitative changes in the protein molecules produced (Linz \& Orlowski, 1984). The data in these studies strongly implied, but could not definitively demonstrate, selective translation of several specific messages from the total mRNA pool.

In this study we investigated such potential post-transcriptional control by in vitro translation of the total mRNA pool extracted from dormant and germinating sporangiospores of $M$. racemosus. The isotopically-labelled in vitro translation products were analysed by PAGE and autoradiography and were compared with in vivo translation products similarly treated. Results from the in vitro analyses established the presence and relative amounts of specific messages in the total mRNA pool whereas the in vivo analyses ascertained the utilization of these messages in the living cell.

† Present address: Department of Food Science, Michigan State University, East Lansing, MI 48824, USA. 


\section{METHODS}

Organism. $M$. racemosus ( $M$. lusitanicus; $M$. circinelloides) ATCC $1216 \mathrm{~B}$ was used in all experiments.

Sporangiospore production and germination. Sporangiospores were raised, harvested and stimulated to germinate as previously reported (Linz \& Orlowski, 1982, 1984).

Cell-free protein synthesis. The method of Alton \& Lodish (1977) was used to purify total RNA from sporangiospores of $M$. racemosus for in vitro translation. Prior to this extraction procedure, cellular development was stopped at the desired stages and further RNA synthesis was inhibited in the germinating spores by the addition of sodium azide and sodium fluoride (each to a final concn of $10 \mathrm{mM}$ ) to the cultures (Linz \& Orlowski, 1982). The spores were harvested directly into sterile water containing the two inhibitors and the RNA from the dormant spores was extracted. Spores were rapidly collected and washed on membrane filters (Millipore) and were disrupted by grinding them for $10 \mathrm{~min}$ under liquid nitrogen with a sterile mortar and pestle. After purification, the RNA was quantified by measuring the $A_{260}$ of an aqueous solution and was stored at $-70{ }^{\circ} \mathrm{C}$ until further use.

In vitro translation of $M$, racemosus RNA was done in a commercial rabbit reticulocyte cell-free protein synthesizing system (Bethesda Research Laboratories) according to the manufacturer's instructions, except that the final concentration of potassium ion was adjusted to $168 \mathrm{mM}$ after empirical determination that this value enhanced the synthesis of high $M_{\mathrm{r}}$ proteins. A small sample of reaction mixture was collected to measure the incorporation of $\mathrm{L}-\left[{ }^{35} \mathrm{~S}\right]$ methionine into protein in the form of hot TCA-precipitable radioactivity (Orlowski \& Sypherd, 1978). The remainder of each reaction mixture was precipitated with $10 \mathrm{vols} 80 \%(\mathrm{v} / \mathrm{v})$ acetone and cooled on ice for $10 \mathrm{~min}$. The resulting precipitates were collected by centrifugation and were resuspended in the SDS sample buffer described previously (Linz \& Orlowski, 1984). Samples could be stored at $-20{ }^{\circ} \mathrm{C}$ in this form until subjected to electrophoresis.

$P A G E$ of protein. The samples of proteins synthesized in vitro could either be analysed directly by modification (Orlowski, 1979) of the SDS disc-gel electrophoresis procedure of Laemmli (1970) or prepared for the twodimensional gel electrophoretic analysis of O'Farrell (1975) by a modification (Linz \& Orlowski, 1984) of the procedure of Alton \& Lodish (1977). All gels were fixed, stained with Coomassie Blue R-250, photographed and subsequently dried and autoradiographed (Orlowski, 1979). The autoradiographs were photographed in the same way as the gels.

Materials. L- $\left[{ }^{35} \mathrm{~S}\right]$ Methionine $\left(1194 \mathrm{Ci} \mathrm{mmol}^{-1} ; 44 \mathrm{TBq}_{\mathrm{mmol}}^{-1}\right)$ was purchased from New England Nuclear. Biochemicals were either from Sigma or from Bio-Rad unless specified otherwise in the text.

\section{RESULTS AND DISCUSSION}

\section{Analysis of functional $m R N A$ levels in dormant and germinating sporangiospores}

A rabbit reticulocyte in vitro protein synthesizing system was used to analyse mRNA populations in dormant and germinating sporangiospores of $M$. racemosus. Prior to such studies the cell-free system was optimized for programming with purified $M$. racemosus RNA. The incorporation of $\mathrm{L}-\left[{ }^{35} \mathrm{~S}\right]$ methionine into hot TCA-insoluble material displayed a linear relationship with respect to time, throughout a $60 \mathrm{~min}$ incubation period, and with respect to the amount of $M$. racemosus RNA added per reaction mixture, up to $20 \mu \mathrm{g}$ RNA (data not shown). $M$. racemosus RNA stimulated the incorporation of radioactive precursor into protein by approximately 8- to 13-fold above the level of endogenous incorporation (Table 1). In the reaction mixture containing $1 \mu \mathrm{g}$ pure rabbit globin mRNA incorporation was stimulated 14fold. Since approximately $3-4 \%$ of $M$. racemosus spore RNA is polyadenylated (Linz \& Orlowski, 1982), $20 \mu \mathrm{g}$ of this RNA should stimulate $60-80 \%$ (about 8-9-fold over endogenous) as much incorporation of labelled isotope as $1 \mu \mathrm{g}$ of globin $\mathrm{mRNA}$. In fact, stimulation was at this level or higher, suggesting that $M$. racemosus RNA was translated in the reticulocyte system with an efficiency similar to that of a native message.

RNA from dormant spores was $60-70 \%$ as efficient in the stimulation of protein synthesis in vitro as RNA purified from spores that had been germinated for 15 min (Table 1). RNA, in general, and polyadenylated RNA, in particular, are not synthesized at detectable levels during this very early period of germination (Linz \& Orlowski, 1982), suggesting that the increase in translation efficiency may be due to the processing of stored mRNA rather than de novo synthesis of mRNA. Another possible explanation might be that RNA from dormant spores suffers damage not incurred by RNA from germinating spores during the purification procedure. However, since both systems are processed using identical procedures there would seem to be little opportunity for differential damage. A similar observation of reduced efficiency 
Table 1. Incorporation of $\mathrm{L}-\left[{ }^{35} S\right]$ methionine into hot TCA-insoluble material in a rabbit reticulocyte cell-free protein synthesizing system programmed with $M$. racemosus $R N A$

Total cellular RNA was purified from dormant spores and from germinating spores after $15,30,45$ and $60 \mathrm{~min}$ of germination in YPG medium under air. Each cell-free reaction mixture $(30 \mu \mathrm{l})$ contained either $M$. racemosus RNA $(20 \mu \mathrm{g})$ or globin mRNA $(1 \mu \mathrm{g})$, and was incubated for $60 \mathrm{~min}$. Samples $(5 \mu \mathrm{l})$ were withdrawn and assayed for $\mathrm{L}-\left[{ }^{35} \mathrm{~S}\right]$ methionine incorporated into protein. RNA purification, in vitro translation, and assay of radioactive protein products were done as indicated in the text.

\begin{tabular}{|c|c|}
\hline Source of RNA & $\begin{array}{c}10^{-5} \times \text { TCA-precipitable } \\
\text { L-[35 }] \text { methionine incorporation } \\
\text { (c.p.m. per } 5 \mu \text { l sample) }\end{array}$ \\
\hline Dormant spore & $4 \cdot 29$ \\
\hline $15 \mathrm{~min}$ & 7.06 \\
\hline $30 \mathrm{~min}$ & $6 \cdot 26$ \\
\hline $45 \mathrm{~min}$ & $7 \cdot 11$ \\
\hline $60 \mathrm{~min}$ & $6 \cdot 29$ \\
\hline No added RNA & 0.56 \\
\hline Globin mRNA & 7.83 \\
\hline
\end{tabular}

of translation of RNA from dormant spores relative to RNA from developing hyphae has also been reported in the case of the related fungus Rhizopus stolonifer and was also inexplicable. (Freer \& Van Etten, 1978). After the initial increase in translation efficiency, the level of translatable $\mathrm{mRNA}$ remained relatively constant throughout the first $60 \mathrm{~min}$ of germination.

\section{$P A G E$ analyses of $M$. racemosus proteins synthesized in vitro}

Fig. 1 displays the two-dimensional separation of proteins synthesized in vivo during sporangiospore formation and during two $15 \mathrm{~min}$ intervals of the first hour of sporangiospore germination. These electrophoretograms are similar to previously published results (Linz \& Orlowski, 1984) and are included to facilitate a comparison between the proteins synthesized in vitro from extracted mRNA pools and those synthesized in the living system.

A high degree of translational fidelity was exhibited when labelled proteins were analysed on one-dimensional SDS disc-gel electrophoresis gels. Most discernible bands labelled in vitro were identical in terms of location and labelling density with those labelled in vivo (data not shown). The $M_{\mathrm{r}}$ distribution of proteins labelled in vitro did not appear significantly different from those labelled in vivo when the potassium ion concentration of the cell-free system was adjusted to its empirically determined optimum (data not shown).

A substantial number of the protein products synthesized in vitro were visible and resolved as individual spots on two-dimensional isoelectric focussing-SDS polyacrylamide gels (Fig. 2). Their $M_{\mathrm{r}}$ values ranged from 13000 to 200000 . Many of these proteins were identical in apparent $M_{\mathrm{r}}$ and isoelectric point, with proteins labelled during in vivo pulses (Fig. 1).

One protein invariably detected on both one- and two-dimensional gels was identified as an endogenous product of the in vitro protein synthesizing system. This protein had an $M_{\mathrm{r}}$ of 47000 and an isoelectric point of about 6.0. The protein spot is marked with an arrow on all the gels in Fig. 2 to avoid possible confusion with $M$. racemosus proteins.

PAGE analysis of in vitro translation products showed that the stable mRNA in dormant sporangiospores of $M$. racemosus was stored in a form which produced proteins, most of which were identical to those synthesized in vivo during the first $30 \mathrm{~min}$ of germination. The ability of spores to store but not utilize functional mRNA constitutes a form of translational regulation of gene expression.

Several proteins that accumulated during spore formation (Fig. $1 a$ ) were not synthesized in vivo during early germination (Fig. $1 b, c$ ). These proteins have already been designated $2,48,56$, 66 and 67 in a previous publication. Analysis of mRNA populations by in vitro protein synthesis revealed the absence of translatable message for proteins 2, 56, 57, 66 and 67 in both dormant and germinating spores (Fig. 2). The mRNA for protein 48 was present in dormant spores 

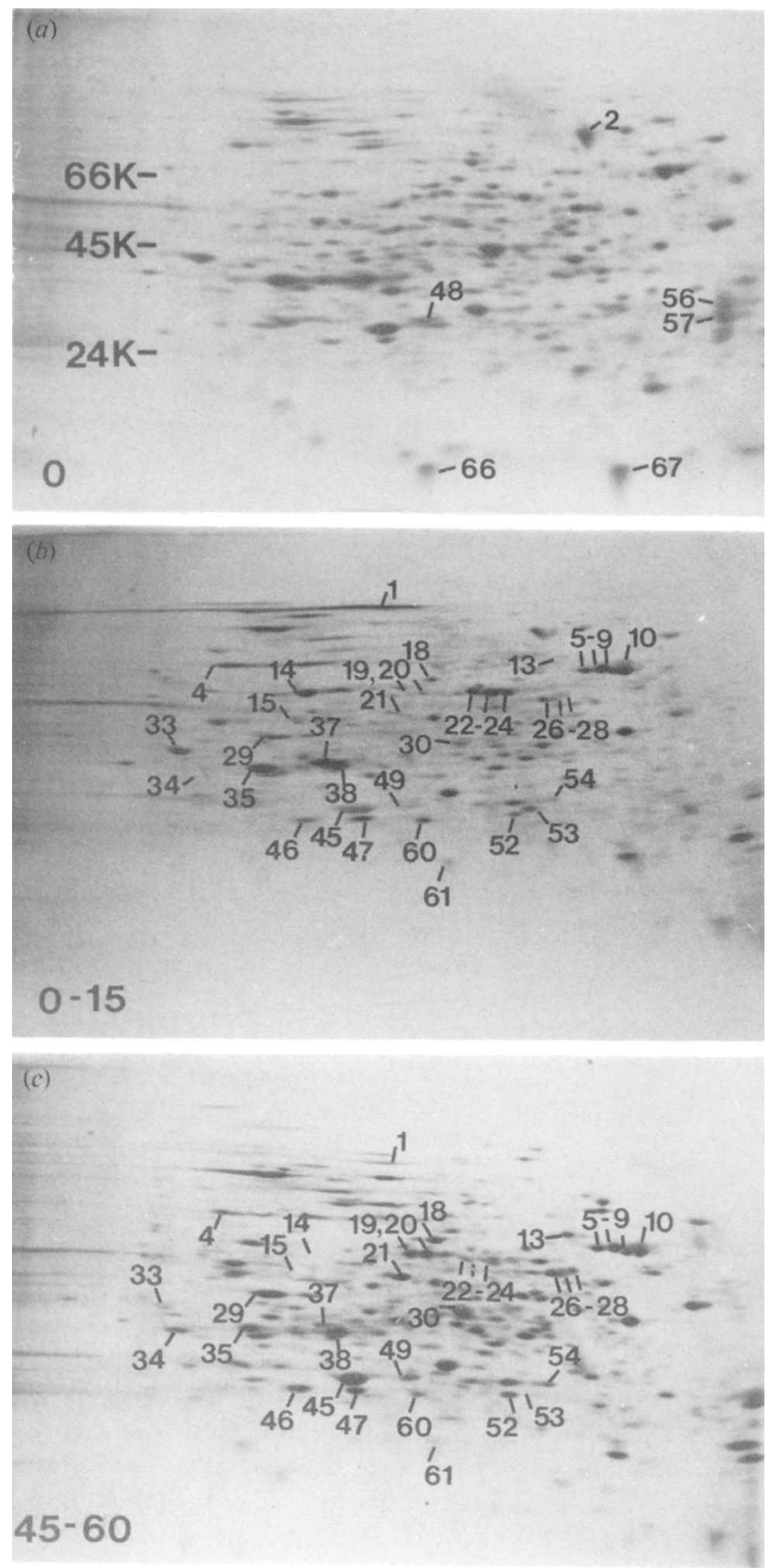

Fig. 1. Autoradiographs of two-dimensional polyacrylamide gels of dormant $M$. racemosus sporangiospores pre-labelled with L-[ ${ }^{35}$ S $]$ methionine and of germinating $M$. racemosus sporangiospores pulse-labelled with $\mathrm{L}-\left[{ }^{35} S\right]$ methionine. Spores pre-labelled with $\left.\mathrm{L}-{ }^{35} \mathrm{~S}\right]$ methionine during spore formation were harvested directly into sterile water containing cycloheximide $\left(250 \mu \mathrm{g} \mathrm{ml}^{-1}\right)$. Proteins of germinating spores were pulse-labelled with $\mathrm{L}-\left[^{35} S\right]$ methionine during four consecutive $15 \mathrm{~min}$ periods in the first $60 \mathrm{~min}$ of germination. Proteins were extracted and electrophoresed as indicated in the text. Protein samples $(200 \mu \mathrm{g})$ containing $8.0 \times 10^{-4} \mathrm{c}$.p.m. were loaded onto the first dimension gels. (a) Pre-labelled proteins of dormant spores; (b) proteins pulse-labelled during the first $15 \mathrm{~min}$ of germination; $(c)$ proteins pulse-labelled during the $45-60 \mathrm{~min}$ interval after initiation of germination. The mobilities of $M_{\mathrm{r}}$ standards, BSA, $66000(66 \mathrm{~K})$; ovalbumin, 45000 (45 K); trypsinogen, 24000 $(24 \mathrm{~K})$, are indicated at the left of panel $(a)$. A more complete analysis of proteins synthesized in vivo during the first hour of $M$. racemosus sporangiospore germination was presented previously (Linz \& Orlowski, 1984). 
although it was apparently degraded or inactivated early in germination and was not translated in vivo or in vitro during germination.

Four proteins $(4,13,60$ and 61$)$ were synthesized in vivo during the first $30 \mathrm{~min}$ of germination but not during spore formation (Fig. 1). Translatable mRNA specifying proteins 4 and 60 was detected in dormant spores (Fig. $2 a$ ). Thus, developing sporangiospores may have the ability not only to store mRNA in a stable form but to selectively translate mRNA molecules specific for proteins required during spore maturation and to avoid translating stored mRNA molecules specific for proteins required during early spore germination. This ability to selectively withhold the translation of specific mRNA populations has been described in other eukaryotic systems (Papaconstantinou, 1967; Slater \& Spiegelman, 1966; Stavy \& Gross, 1969) and is often referred to as 'masking'.

Translatable mRNA for protein 61 appeared within the first $15 \mathrm{~min}$ of germination and remained at a constant level throughout the first $60 \mathrm{~min}$ of germination (Fig. $2 b-e$ ). Since mRNA synthesis is undetectable during the first $20 \mathrm{~min}$ of germination (Linz \& Orlowski, 1982), it may be that the mRNA for protein 61 is synthesized as a precursor and stored in the dormant spore. Once germination is initiated the precursor may be processed to the final translatable form. An alternative hypothesis that cannot rigorously be excluded by the existing data would posit large quantities of mRNA specifying protein 61 being rapidly and quite selectively transcribed and translated within the first $15 \mathrm{~min}$ of germination. Considering the known complexity of eukaryotic mRNA synthesis and maturation and the separation of translation from transcription through space and time in these systems, we consider this explanation less plausible than the first. The massive recruitment of free ribosomal subunits into active polyribosomes, which occurs immediately upon introduction of sporangiospores into liquid medium (Linz \& Orlowski, 1982), suggests that most proteins whose synthesis is strongly detectable by the present techniques within the first $15 \mathrm{~min}$ period of germination would have been made from pre-existing messages.

Translatable mRNA for protein 13 was not detected in this analysis. The latter observation may imply that this protein is generated by a post-translational event in vivo which cannot be duplicated in the in vitro system. Alternatively, formation of the appropriate translation initiation complex may not take place in vitro due to the specificity of the components involved.

Levels of translatable mRNA specific for several proteins $(5-9,31,46,60$ and 61) remained constant during the first 60 min of germination (Fig. 2a-e). Proteins 5-9, 31 and 47 were also synthesized at a constant rate in vivo during this period (Fig. 1). However, proteins 60 and 61 were synthesized at a decreasing rate in vivo, suggesting that the level of translation of these proteins is not determined by the amount of available mRNA. Expression of the genes specifying these proteins is therefore regulated by a mechanism that may be post-transcriptional or translational in nature.

The rates of in vivo synthesis of several proteins quantitatively changed during the first $60 \mathrm{~min}$ of germination. These changes correlated well with alterations in the levels of specific translatable mRNA molecules detected by an in vitro assay. Proteins 26, 27, 28 and 46 showed increasing rates of synthesis in vivo, reflecting increased levels of translatable mRNA, whereas proteins $1,14,15,33,35,37$ and 53 displayed decreasing rates of synthesis in vivo, reflecting decreases in the concentrations of translatable mRNA molecules (Fig. 2a-e). It is probable that most of these proteins have their expression regulated primarily at the level of transcription (synthesis of RNA) or post-transcription (inactivation or degradation of RNA).

Protein 45 is perhaps the most convincing example observed in this study of a gene product that may be subject to regulation at the translational level during germination. Protein 45 is synthesized at increasing rates throughout early germination, yet the level of translatable mRNA was found to decrease significantly during this time. Several explanations may account for this observation, including changes in the affinity between mRNA and ribosome and alterations in the rate of ribosome movement along the mRNA.

Although conclusions cannot be drawn about the specific mechanisms of regulation on the basis of the present data, this study has provided much evidence to suggest that protein synthesis is regulated at multiple levels during the formation and germination of $M$. racemosus sporangiospores. These levels, at a minimum, encompass differential transcription, post- 

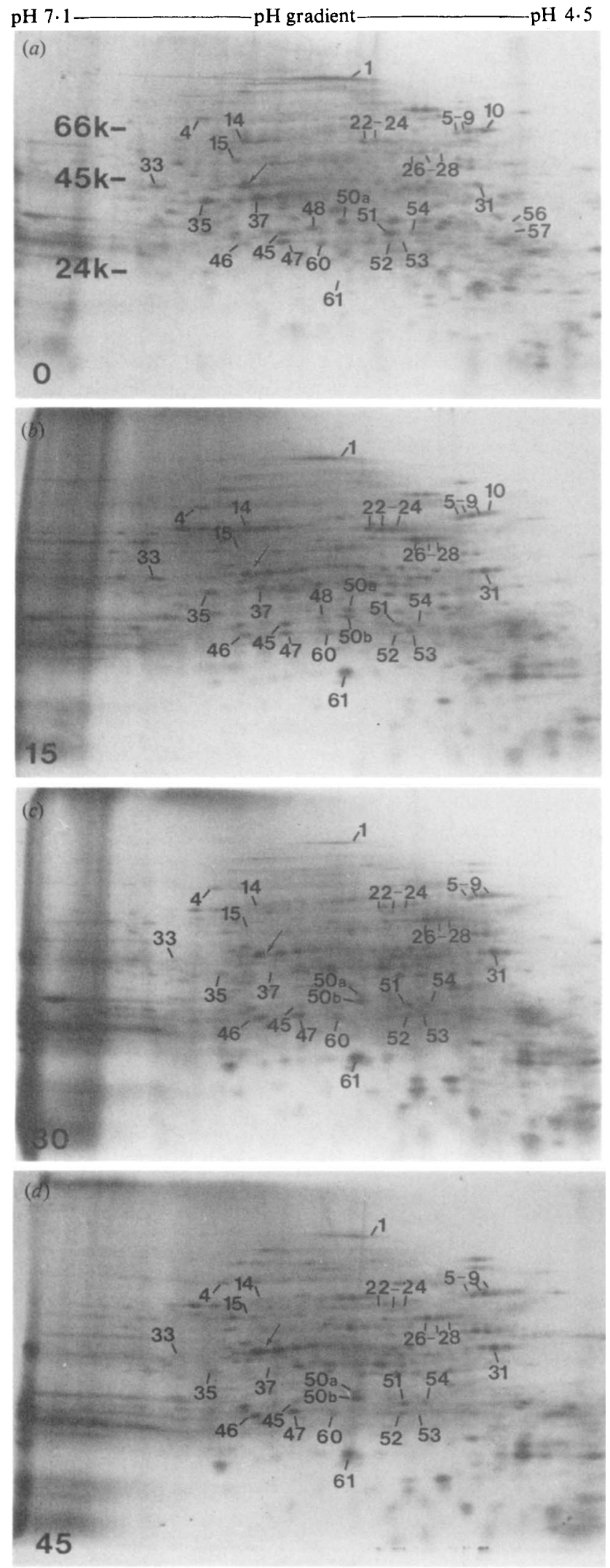


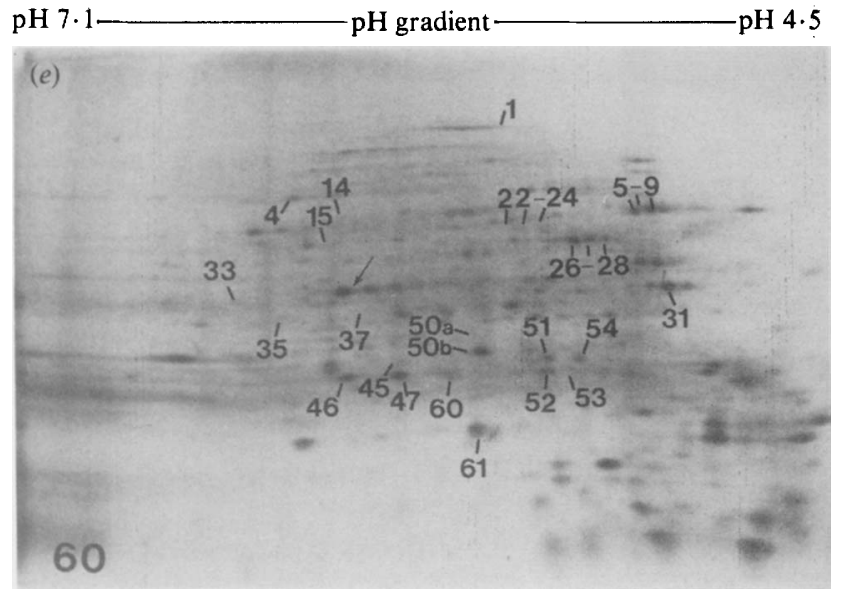

\begin{abstract}
Fig. 2. Two-dimensional isoelectric focussing SDS-PAGE analysis of protein products from a rabbit reticulocyte in vitro protein synthesizing system programmed with $M$. racemosus RNA. Total cellular RNA was purified from dormant sporangiospores and from spore samples collected at 15 min intervals during the first $60 \mathrm{~min}$ of spore germination in YPG under air. Each cell-free reaction mixture $(30 \mu \mathrm{l})$ contained $20 \mu \mathrm{l}$ of one of the Mucor RNA samples. All reaction mixtures were incubated for $60 \mathrm{~min}$ using L- $\left[{ }^{35} S\right]$ methionine as the radioactive label. Protein samples $(5 \mu \mathrm{l})$ containing $4.8 \times 10^{5}-9.5 \times$ $10^{5}$ c.p.m. were treated and electrophoresed as indicated in the text. The resulting gels were dried and autoradiographed. (a) RNA from dormant spores; $(b-e)$ RNA from spores germinated for 15, 30, 45 and $60 \mathrm{~min}$ respectively. $M_{\mathrm{r}}$ markers are as in Fig. 1 . The arrow on each autoradiograph identifies the endogenous protein product labelled in the absence of added RNA.
\end{abstract}

transcriptional processing and selective translation. This study has provided specific examples of gene products upon which these different levels of control are clearly exerted. The logical continuation of this work will focus on several of these, especially those displaying posttranscriptional and translational control. The significance of regulation at these levels may be more apparent and easily discerned in Mucor than in other commonly studied systems of microbial development because of the organism's dimorphic habit. Sporangiospores of $M$. racemosus have two potential morphologic fates: yeast cells or hyphae. The spores may maximize their developmental options by storing mRNA molecules essential to the formation of both cell types and ultimately expressing only those appropriate to the morphogenetic sequence dictated by the environment.

This research was supported by United States Public Health Service grant AI19770, awarded to M. O. by the National Institute of Allergy and Infectious Diseases.

\title{
REFERENCES
}

Alton, T. H. \& Lodish, H. F. (1977). Developmental changes in messenger RNAs and protein synthesis in Dictyostelium discoideum. Developmental Biology 60 , 180-206.

BARNICKI-GARCIA, S. (1973). Fundamental aspects of hyphal morphogenesis. Symposia of the Society for General Microbiology 23, 245-267.

Freer, S. N. \& VAN ETten, J. L. (1978). Changes in messenger RNAs and protein synthesis during germination of Rhizopus stolonifer sporangiospores. Experimental Mycology 2, 313-325.

LAEMMLI, U.K. (1970). Cleavage of structural proteins during the assembly of the head of bacteriophage T4. Nature, London 227, 680-685.

LINZ, J. E. \& ORLowSKI, M. (1982) Stored mRNA in sporangiospores of the fungus Mucor racemosus. Journal of Bacteriology 150, 1138-1144.

Linz, J. E. \& ORLowsKI, M. (1984) Differential gene expression during aerobic germination of Mucor racemosus sporangiospores. Journal of Bacteriology 159, 965-972.

O'FARRELl, P. H. (1975). High resolution two-dimensional electrophoresis of proteins. Journal of Biological Chemistry 250, 4007-4021.

ORLOWSKI, M. (1979). Changing pattern of cyclic AMP-binding proteins during germination of Mucor racemosus sporangiospores. Biochemical Journal 182, 547-554.

ORLOWSKI, M. \& SYPHERD, P. S. (1978). Regulation of macromolecular synthesis during hyphal germ tube emergence from Mucor racemosus sporangiospores. Journal of Bacteriology 134, 76-83.

Papaconstantinou, J. (1967). Molecular aspects of lens cell differentiation. Science 156, 338-346.

Slater, D.W. \& Spiegelman, S. (1966). An estimation of genetic messages in the unfertilized echinoid egg. Proceedings of the National Academy of Sciences of the United States of America 56, 164-170. 
Stavy, L. \& Gross, P. R. (1969). Availability of mRNA from translation during normal and transcription blocked development. Biochimica et biophysica acta 182, 203-213.

Sypherd, P. S., Borgia, P. T. \& Paznokas, J. L. (1979). Biochemistry of dimorphism in the fungus Mucor. Advances in Microbial Physiology 18, 68-104.

TRIPP, M. L. \& PAZNOKas, J. L. (1981). Relationship between sporulation medium and germination ability of Mucor racemosus sporangiospores. Journal of General Microbiology 127, 35-43.
Tripp, M. L. \& Paznokas, J. L. (1982a). Glucoseinitiated germination of Mucor racemosus sporangiospores. Journal of General Microbiology 128, 477-483. TRIPP, M. L. \& PAZNOKAS, J. L. (1982b). Role of amino acids and endogenous protein in the germination of Mucor racemosus sporangiospores. Journal of General Microbiology 128, 485-495.

WERTMAN, K. F. \& PAZNOKAS, J. L. (1981). Effects of cyclic nucleotides upon the germination of Mucor racemosus sporangiospores. Experimental Mycology 5, 314-322. 